\title{
The Inactivation of JAK2/STAT3 Signaling and Desensitization of M1 mAChR in Minimal Hepatic Encephalopathy (MHE) and the Protection of Naringin Against MHE
}

\author{
Saidan Ding ${ }^{a}$ Jiangnan $\mathrm{Hu}^{\mathrm{b}}$ Jianjing Yang ${ }^{\mathrm{b}}$ Leping Liu ${ }^{\mathrm{a}}$ Weilong Huang ${ }^{\mathrm{b}}$ \\ Xialong Gu ${ }^{b}$ Yiru Ye ${ }^{c}$ Lijie Huang ${ }^{b}$ Yong Liang ${ }^{a}$ Bicheng Chen ${ }^{a}$ Qichuan Zhuge ${ }^{b}$ \\ aZhejiang Provincial Key Laboratory of Aging and Neurological Disease Research, Department of \\ Surgery, the First Affiliated Hospital of Wenzhou Medical University, ${ }^{b}$ Neurosurgery Department, the \\ First Affiliated Hospital of Wenzhou Medical University, 'Department of Computer, Wenzhou Medical \\ University, Wenzhou, China
}

\section{Key Words}

Minimal hepatic encephalopathy (MHE) • Dopamine $\bullet$ Memory impairment $\bullet$ JAK2/STAT3 axis - M1-type muscarinic acetylcholine receptor (M1 mAChR)

\begin{abstract}
Background: We previously reported that elevation of intracranial dopamine (DA) levels from cirrhotic livers is implicated in the pathogenesis of minimal hepatic encephalopathy (MHE). Intracellular events in neurons, which lead to memory loss in MHE by elevated DA, however, remain elusive. Methods: In our present study, an MHE rat model, a DA intracerebroventricularly (i.c.v.) injected rat model and DA-treated primary cortical neurons (PCNs) were used to study this issue using behavioral tests, double-labeled fluorescent staining, immunoblotting, and semi-quantitative RT-PCR. Results: Cognitive impairment was observed in MHE rats and DA (10 $\mu$ g, i.c.v.)-treated rats. The levels of DA in the cerebral cortex of both MHE and DA $(10 \mu \mathrm{g})$-treated rats were increased. DA conversely modulated the p-JAK2/p-STAT3 levels in PCNs. In accordance, DA downregulated an anacetylcholineproducing enzyme, choline acetyltransferase (ChAT), and desensitized the M1-type muscarinic acetylcholine receptor (M1 mAChR). Furthermore, naringin completely restored cognitive function in MHE/DA $(10 \mu \mathrm{g})$-treated models by activating the JAK2/STAT3 axis, paralleling the upregulation of ChAT and sensitization of M1 mAChR. Conclusions: We propose a hypothesis accounting for memory impairment related to MHE: DA-dependent inactivation of the JAK2/ STAT3 axis causes memory loss through cholinergic dysfunction. Our findings provide not only a novel pathological hallmark in MHE but also a novel target in MHE therapy.
\end{abstract}

S. Ding and J. Hu contributed equally to this work.

Copyright (C) 2014 S. Karger AG, Basel 


\section{Cellular Physiology and Biochemistry}

Cell Physiol Biochem 2014;34:1933-1950

\begin{tabular}{l|l}
\hline DOI: $10.1159 / 000366391$ & (C) 2014 S. Karger AG, Basel
\end{tabular}

www.karger.com/cpb

Ding et al.: Naringin Against MHE via JAK2/STAT3

\section{Introduction}

The Janus kinases (JAKs) are a family of non-receptor protein tyrosine kinases (PTKs) that consists of four mammalian isoforms: JAK1, JAK2, JAK3, and TYK2. The best established downstream effector of JAK is the signal transducer and activator of transcription (STAT) family. Seven STAT isoforms, named STAT1 to STAT4, STAT5A, STAT5B, and STAT6, have been identified. Once phosphorylated by JAK, STATs dimerize and are translocated to the nucleus, where they regulate the expression of many genes [1-3]. Indeed, a model of cognitive dysfunction has been proposed in Alzheimer's disease (AD) [4]. The Janus kinase 2 (JAK2)/signal transducer and activator of transcription 3 (STAT3) axis upregulates choline acetyltransferase (ChAT) expression in presynapses (pre), leading to the increased release of acetylcholine (ACh), which binds to M1 mAChR on postsynapses (post) in the synaptic cleft, sensitizing M1 mAChR.

There is increasing evidence of linkage of the JAK2/STAT3 pathway to memory in AD $[4,5]$ and a genetic model of aging [6]. Several studies of the function of M1 mAChR found that M1 mAChR-deficient rats shows severe memory impairment [7] and that M1 mAChR agonists attenuated memory impairment in an AD model [8]. In accordance, AG490 (a JAK inhibitor)-injected rats had memory impairment, and a mild reduction in the number of ChAT-positive neurons was observed in the medial septa of AG490-injected rats [4]. Minimal hepatic encephalopathy (MHE) has the characteristic of subtle changes in cognitive function [9]. Our previous study found that the cognitive impairment in MHE may be associated with elevated dopamine (DA) of cirrhotic livers: the DA level was elevated in cirrhotic livers, and DA crossed the blood-brain barrier (BBB), went into the brains of MHE rats, and inhibited learning and memory [10]. Therefore, the JAK2/STAT3 pathway and downstream M1 mAChR may have implications in the MHE-relevant memory impairment by DA.

Many plant species containing flavonoids have been widely used in traditional medicine. Recent epidemiological and dietary interventional studies, both in humans and animals, suggest that these flavonoids prevent and delay neurodegeneration, especially in agedpopulation cognitive dysfunction [11]. Naringin, a well-known flavanone glycoside of citrus fruits, has been reported to attenuate behavioral alterations and cognitive impairment in kainic acid-induced epilepsy models [12] and 3-nitropropionic acid-induced Huntington models [13]. Moreover, naringin administration improves cognitive deficits in a mouse model of AD [14], as well as colchicine- [15], D-galactose- [16] and aluminium [17]-induced learning and memory impairment models. It has also been shown that naringin enhances memory activity in unstressed and stressed rats, probably by decreasing brain AChE activity [18].

In our present study, we delineate the role of the JAK2/STAT3 signaling axis in MHErelated memory loss, focusing on the effect of elevated DA, originating from cirrhotic liver, in the brains of MHE models on the activity of the JAK2/STAT3 axis. We also address the impact of DA on cholinergic neurotransmission through the JAK2/STAT3 axis.

\section{Materials and Methods}

\section{MHE models and treatments}

A total of 50 Sprague-Dawley rats (Experimental Animal Center of The Chinese Academy of Sciences in Shanghai) weighing 220-250 g were used. Rats were housed under controlled conditions of temperature $\left(24 \pm 1^{\circ} \mathrm{C}\right)$ and light $(12 \mathrm{~h} \mathrm{light}$ starting at 07:00 am), and all experiments were carried out in accordance with the Guidelines laid down by the Ethics Committees of the First Affiliated Hospital of Wenzhou Medical University regarding the care and use of animals for experimental procedures.

Before experimenting, all animals underwent a series of behavioral tests: a Y-maze (YM), open-field tests (OF), an elevated-plus maze (EPM), and a water-finding task (WFT). Normal values of these behavioral tests were obtained. Rats were then randomly divided into two groups: a control group $(\mathrm{n}=20)$ and a thioacetamide (TAA) group ( $\mathrm{n}=30$ ). MHE was induced by intraperitoneal injection (i.p.) of TAA (200 mg/kg in normal saline, Sigma-Aldrich) twice per week for 8 weeks. Behavioral tests were performed for all rats 


\section{Cellular Physiology and Biochemistry}

Cell Physiol Biochem 2014;34:1933-1950

\begin{tabular}{l|l}
\hline DOI: $10.1159 / 000366391$ & (C) 2014 S. Karger AG, Basel
\end{tabular}

www.karger.com/cpb

Ding et al.: Naringin Against MHE via JAK2/STAT3

again. Rats included in the MHE group had to meet the following criteria: a) to exclude hepatic cirrhosis rats without MHE, at least one of the values of all behavioral tests in the MHE group must be significantly higher than that of the control group; b) to exclude hepatic encephalopathy (HE) rats with HE, EEG could show no typical slow wave of HE in the MHE group [19]. At $24 \mathrm{~h}$ after MHE modeling, i.p. naringin (in saline, $80 \mathrm{mg} /$ $\mathrm{kg}$ ) was injected three times at 48-h intervals. At $24 \mathrm{~h}$ after naringin treatment, carbamylcholine chloride (carbachol, CCh) $(0.2 \mathrm{mg} / \mathrm{kg}$, in saline) was also administered for $30 \mathrm{~min}$ by i.p. injection. Then rats were anesthetized with intramuscular xylazin $(16 \mathrm{mg} / \mathrm{kg})$, blood was drawn from the aorta abdominalis, and tissues of the liver and cerebral cortex were collected.

\section{DA-treated rat models and treatments}

Rats were anesthetized with intramuscular xylazin $(16 \mathrm{mg} / \mathrm{kg})$ followed by ketamine $(100 \mathrm{mg} / \mathrm{kg})$. Intracerebroventricular (i.c.v.) injection of dopamine jydrochloride $(1 \mu \mathrm{g} / 3 \mu \mathrm{l}$ and $10 \mu \mathrm{g} / 3 \mu \mathrm{l}$ in saline) was performed stereotaxically in the left lateral ventricles of rats (anterior-posterior, $+0.3 \mathrm{~mm}$; lateral, 1.0 $\mathrm{mm}$; horizontal, $3.0 \mathrm{~mm}$ from the bregma) $(\mathrm{n}=15)$. At 7 days after injection, rats were tested in an $\mathrm{OF}$ test, a YM, an EPM test and a WFT test. After the behavioral tests, i.p. naringin ( $80 \mathrm{mg} / \mathrm{kg}$ ) was also injected three times at 48 -h intervals, or CCh $(0.2 \mathrm{mg} / \mathrm{kg}$, in saline) was administered to the rats for $30 \mathrm{~min}$. At $12 \mathrm{~h}$ after treatment, rats were tested in the YM. Then rats were anesthetized with intramuscular xylazin (16 mg/ $\mathrm{kg})$, blood was drawnfrom the aorta abdominalis, and tissues of the cerebral cortex were collected.

\section{Behavioral tests}

OF were performed as described [20]. Briefly, rats were individually placed at the center of a $10 \times 10$ $\mathrm{cm}$ gray plastic field (with a black grid spaced at $20 \mathrm{~cm}$ intervals) surrounded by a $20 \mathrm{~cm}$ wall, and allowed to move freely for $3 \mathrm{~min}$. Ambulation was measured, defined as the total grid line crossing.

The apparatus for the YM was made of gray plastic, with each arm $40 \mathrm{~cm}$ long, $12 \mathrm{~cm} \mathrm{high,} 3 \mathrm{~cm}$ wide at the bottom and $10 \mathrm{~cm}$ wide at the top [20,21]. The three arms were connected at an angle of $120^{\circ}$. Rats were individually placed at the end of an arm and allowed to explore the maze freely for $8 \mathrm{~min}$. Total arm entries and spontaneous alternation percentage (SA\%) were measured. SA\% was defined as the ratio of the arm choices that differed from the previous two choices (successful choices) to the total choices during the run (total entry minus two, because the first two entries could not be evaluated). For example, if a rat made 10 entries, such as 1-2-3-2-3-1-2-3-2-1, there were 5 successful choices out of 8 total choices (10 entries minus 2).

The elevated-plus maze (EPM) apparatus was made of four crossed arms [20, 22]. Two arms were open $(50 \times 10 \mathrm{~cm}$ gray plastic floor plate without wall), whereas the other two were closed (same floor plates with 20 -cm-high transparent acrylic wall). The maze was set at $100 \mathrm{~cm}$ above the floor. Rats were allowed to explore the maze freely for $90 \mathrm{~s}$. Examined parameters were: (1) transfer latency (TL, the time elapsed until the first entry to a closed arm); (2) duration of the first stay in a closed arm (1 $1^{\text {st }}$ stay, the time from the first entry into a closed arm to the first escape from the arm); (3) cumulative time spent in both open and closed arms.

A WFT was performed to analyze latent learning or retention of spatial attention of the rats [20, 23]. The testing apparatus consisted of a gray plastic rectangular open field $\left(50 \times 30 \mathrm{~cm}\right.$, with a black $10-\mathrm{cm}^{2}$ grid) with a $15-\mathrm{cm}$ wall and a cubic alcove $(10 \times 10 \times 10 \mathrm{~cm})$ attached to the center of one longer wall. A drinking tube was inserted through a hole at the center of the alcove ceiling, with the tip of the tube placed at $5 \mathrm{~cm}$ for training or at $7 \mathrm{~cm}$ for the trial from the floor. A rat was first placed at the near-right corner of the apparatus and allowed to explore it freely for $3 \mathrm{~min}$. Rats were omitted from the analysis when they could not find the tube within the 3-min exploration. After the training session, rats were deprived of water for 24 $h$. In the trial session, rats were again individually placed at the same corner of the apparatus and allowed to find and drink the water in the alcove. The elapsed times until the first entry into the alcove (entry latency, EL), until the first touching, sniffing or licking of the water tube (contact latency, CL) and until the initiation of drinking from the water tube (drinking latency, DL) were measured.

\section{Histopathology}

Liver tissues were fixed in $10 \%$ formalin for $24 \mathrm{~h}$ and then paraffin-embedded using an automated tissue processor; $5 \mu \mathrm{m}$ sections were stained with hematoxylin and eosin or Masson and subjected to histopathological examination. 


\section{Cellular Physiology and Biochemistry}

Cell Physiol Biochem 2014;34:1933-1950

Cell culture and treatments

Primary cortical neurons (PCNs) were prepared from 1-day-old Sprague-Dawley rat pups [24]. Cells were dissociated from freshly dissected cerebral cortex by mechanical disruption in the presence of trypsin and DNase and then plated in poly-L-lysine-precoated six-well plates. Cells were seeded at a density of $2 \times 10^{6}$ cells/well in Neurobasal Medium (1X) supplemented with $0.5 \mathrm{mM}$ GlutaMAX-I, B-27 and incubated at $37^{\circ} \mathrm{C}$, $5 \% \mathrm{CO}_{2}$. The medium was changed after four days. Then cells were incubated with DA (final concentrations of 1,5 and $10 \mu \mathrm{M}$ ) in the presence or absence of naringin (50 $\mu \mathrm{M})$, interleukin-6 (IL-6) ( $50 \mathrm{ng} / \mathrm{ml}$ ), tacrine (1 $\mu \mathrm{M})$ or AG490 $(1 \mu \mathrm{M})$ for $24 \mathrm{~h}$. For ERK phosphorylation assays, Cells were then washed twice with serumfree medium and treated with CCh $(10 \mu \mathrm{M}, \mathrm{ddw})$ for 5 min.

\section{Determination of DA levels}

The analyses were performed with an HPLC system consisting of a Model 100A pump (Altex Scientific, Berkeley, CA), an Eicopack MA-ODS reversed-phase column (250 x 4.6 mm, i.d., packed with 7-zm particles; Eicom Co., Kyoto, Japan), a Model 7125 sample injector (Rheodyne, Berkeley, CA), and a Model 100 electrochemical detector with a WE-3G carbon graphite working electrode (Eicom Co.), with the oxidation potential set at $0.7 \mathrm{~V}$ vs. a $\mathrm{Ag} / \mathrm{AgCl}$ reference electrode for detecting DA. The HPLC system was assembled so that the analytes separated on the HPLC column flowed first through the ultraviolet absorbance detector, then through the electrochemical detector. Column temperature was maintained at $29^{\circ} \mathrm{C}$ with a temperaturecontrolled water bath. The mobile phase consisted of an 89:11 (v/v) mixture of methanol with sodium citrate buffer ( $10 \mathrm{mmol} / \mathrm{l}, \mathrm{pH} 3.1$ ) that contained $10 \mu \mathrm{mol}$ EDTA·2Na, $925 \mu \mathrm{mol}$ sodium 1-octanesulfonate, and $7.18 \mathrm{mmol}$ triethylamine per liter. This mobile phase was delivered at a flow rate of $1.0 \mathrm{ml} / \mathrm{min}$, and was filtered through a $0.5 \mu \mathrm{m}$ (pore size) filter membrane (Toyo Roshi Co., Ltd., Tokyo, Japan) under reduced pressure. All chromatograms were recorded and the areas under the peaks of the respective analytes were integrated with a Model D-2000 Chromato-Integrator (Hitachi Ltd., Tokyo, Japan).

Double-labeled fluorescent staining for tissues and fluorescent staining for PCNs

For tissues: The endogenous peroxidase activity of $4 \mu \mathrm{m}$ frozen cerebral cortex sections fixed in acetone or $4 \%$ formaldehyde was blocked with $0.03 \% \mathrm{H}_{2} \mathrm{O}_{2}$ if appropriate.

For PCNs: PCNs were seeded and cultured on glass coverslips precoated with $0.01 \%$ poly-L-lysine (Sigma-Aldrich) for $1 \mathrm{~h}$. After the cells were treated with DA (final concentrations of 1, 5 and $10 \mu \mathrm{M}$ ) for 24 h, they were fixed with $4 \%$ paraformaldehyde for $30 \mathrm{~min}$ and then treated with $0.1 \%$ Triton X-100 for 10 min at room temperature.

Sections were blocked with PBS containing 5\% normal goat serum for $1 \mathrm{~h}$ at room temperature. Sections were then incubated overnight at $4^{\circ} \mathrm{C}$ with diluted primary antibodies to the following targets: p-JAK2, p-STAT3, ChAT (Santa Cruz Biotech), 1:1000; p44/p42 p-ERK (Santa Cruz Biotech), 1:3000; M1 mAChR, MAP2 (Abcam), 1:250. Binding of primary antibodies was detected by incubating the sections for 30 min with Alexa Fluor 488 (green)/Alexa Fluor 594 (red) conjugated secondary antibody.

\section{Immunoblotting (IB)}

For ChAT/M1 mAChR assays, the cerebral cortex tissues or PCNs were harvested in a lysis buffer (50 mM Tris HCl, pH 7.4, 150 mM NaCl, 1\% Triton-X100, 1 mM PMSF, $2 \mu \mathrm{g} / \mathrm{ml}$ Aprotinin, $2 \mu \mathrm{g} / \mathrm{ml}$ Leupeptin, 1.5 mM EDTA) (Sigma-Aldrich).

For JAK2/STAT3/ERK phosphorylation assays, the cerebral cortex tissues or PCNs were homogenized in the above lysis buffer with the addition of phosphatase inhibitor $\left(1 \mathrm{mM} \mathrm{Na}_{3} \mathrm{VO}_{4}\right)$.

The total amount of protein was determined by bicinchoninic acid protein assay (Amresco). Samples (50 $\mu \mathrm{g}$ protein) were separated by 10\% SDS-PAGE and electroblotted to PVDF membranes, which were blocked by incubation in 5\% non-fat dry milk dissolved in TBS-T $(150 \mathrm{mM} \mathrm{NaCl}, 50 \mathrm{mM}$ Tris, 0.05\% Tween 20). Following transfer, proteins were probed using a primary antibody: p-JAK 2, JAK 2, p-STAT 3, ChAT, p44/ p42 p-ERK (Santa Cruz Biotech), 1:1000; STAT 3, p44/p42 ERK (Santa Cruz Biotech), 1:3000; M1 mAChR (Abcam), 1:250; glyceraldehyde-3-phosphate dehydrogenase (GAPDH; Abcam), 1:3000. Then horseradish peroxidase-conjugated anti-rabbit secondary antibody was used. After extensive washing, protein bands detected by antibodies were visualized by ECL reagent (Pierce) after exposure to Kodak BioMax film (Kodak). 


\section{Cellular Physiology and Biochemistry}

Cell Physiol Biochem 2014;34:1933-1950

21, 2014

Ding et al.: Naringin Against MHE via JAK2/STAT3

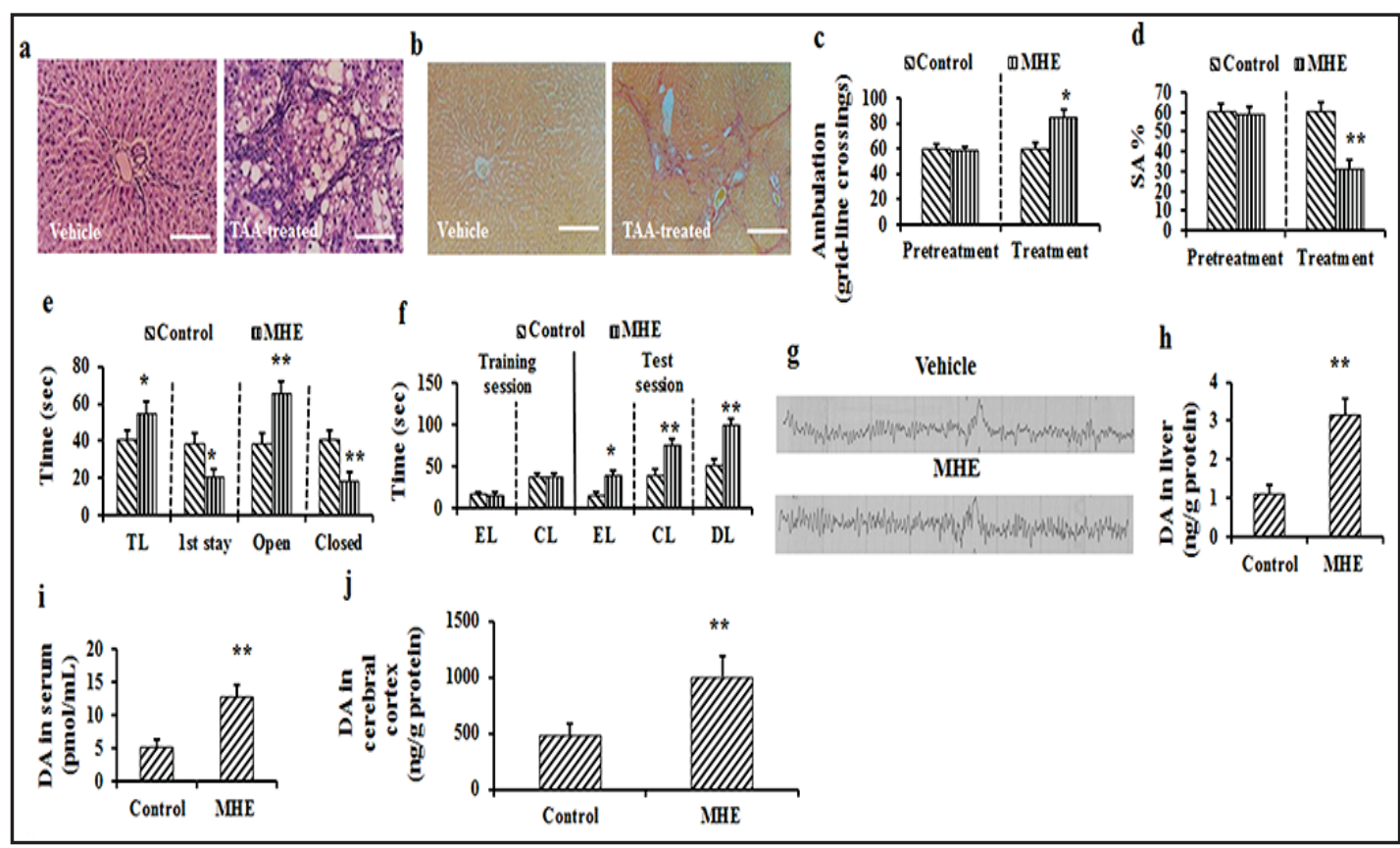

Fig. 1. Memory impairment and elevated DA in MHE models. (a, b) hematoxylin and eosin (a) and Masson (b) staining of liver sections from vehicle and TAA-treated rats. (c) Ambulation in open-field test (OF) of vehicle and TAA-treated rats (pretreatment, left; 8-week treatment, right). (d) Spontaneous alternation percentage (SA\%) in YM of vehicle and TAA-treated rats (pretreatment, left; 8-week treatment, right). (e) Results of elevated-plus maze (EPM) (TL, transfer latency; first stay, duration of the first stay; open, time spent in the open arms; closed, time spent in the closed arms). (f) Results of water-finding task (WFT) (EL, entry latency; CL, contacting latency; DL, drinking latency). (g) The cerebral signal of rats observed in the scalp EEG falls in the Alpha (8-13 Hz) range in both of vehicle and MHE rats. $(h, i, j)$ Levels of DA in the liver (h), serum (i) and cerebral cortex (j) analysed in vehicle and MHE groups (mean \pm SEM). Data are shown as mean \pm SEM. ${ }^{*} \mathrm{P}<0.05,{ }^{* *} \mathrm{P}<0.01$ vs vehicle treatment.

\section{Semi-quantitative RT-PCR}

Total RNA was extracted from PC12 cells that had been treated with or without CLN (100 pM), ADNF9 $(100 \mathrm{pM})$ or IL-6 $(50 \mathrm{ng} / \mathrm{ml})$, with or without the STAT3 inhibitor peptide $(250 \mathrm{nM})$, using TRIzol reagent (Invitrogen). First-strand cDNAs were synthesized from $1 \mu$ g total RNA using Omniscript reverse transcriptase (Qiagen). PCR amplification with Taq DNA polymerase (Sigma-Aldrich) was performed under denaturation at $94^{\circ} \mathrm{C}$ for $30 \mathrm{~s}$, annealing at $60^{\circ} \mathrm{C}$ for $30 \mathrm{~s}$ and elongation at $72^{\circ} \mathrm{C}$ for $90 \mathrm{~s}$, repeating the indicated cycles. The sequences for forward and reverse primers were: ChAT forward 5'-GGGTGATCTGTTCACTCAGTTGAG-3' and reverse 5'-CTCTGGTAAAGCCTGT AGTAAGCC-3'; vesicular acetylcholine transporter (VAChT) forward 5'-AGCGGGCCTTTCATTGATCG-3' and reverse 5'-GGCGCACGTCCACCAGGA AGG-3'; M1 mAChR forward 5'-CTGGTTTCCTTCGTTCTCTG-3' and reverse 5'-GCTGCCTTCTTCTCCTTGAC-3'; GAPDH forward 5'-GAACATCATCCCTGCATCC-3' and reverse 5'-GCTTCACCACCTTCTTGATG-3'.

\section{Statistical analysis}

Data are presented as means \pm SEM. The statistical significance between group comparisons was determined by one-way analysis of variance, followed by a post hoc Tukey's multiple comparison test. Values of $\mathrm{p}<0.05$ or $\mathrm{P}<0.01$ were considered to be statistically significant.

\section{Results}

Memory impairment and elevation of intracranial DA levels in MHE models

$\mathrm{HE}$ and Masson staining in the livers of TAA-treated rats showed bridging or septal fibrosis connecting portal areas and central veins in a portal to portal, portal to central, and/ 


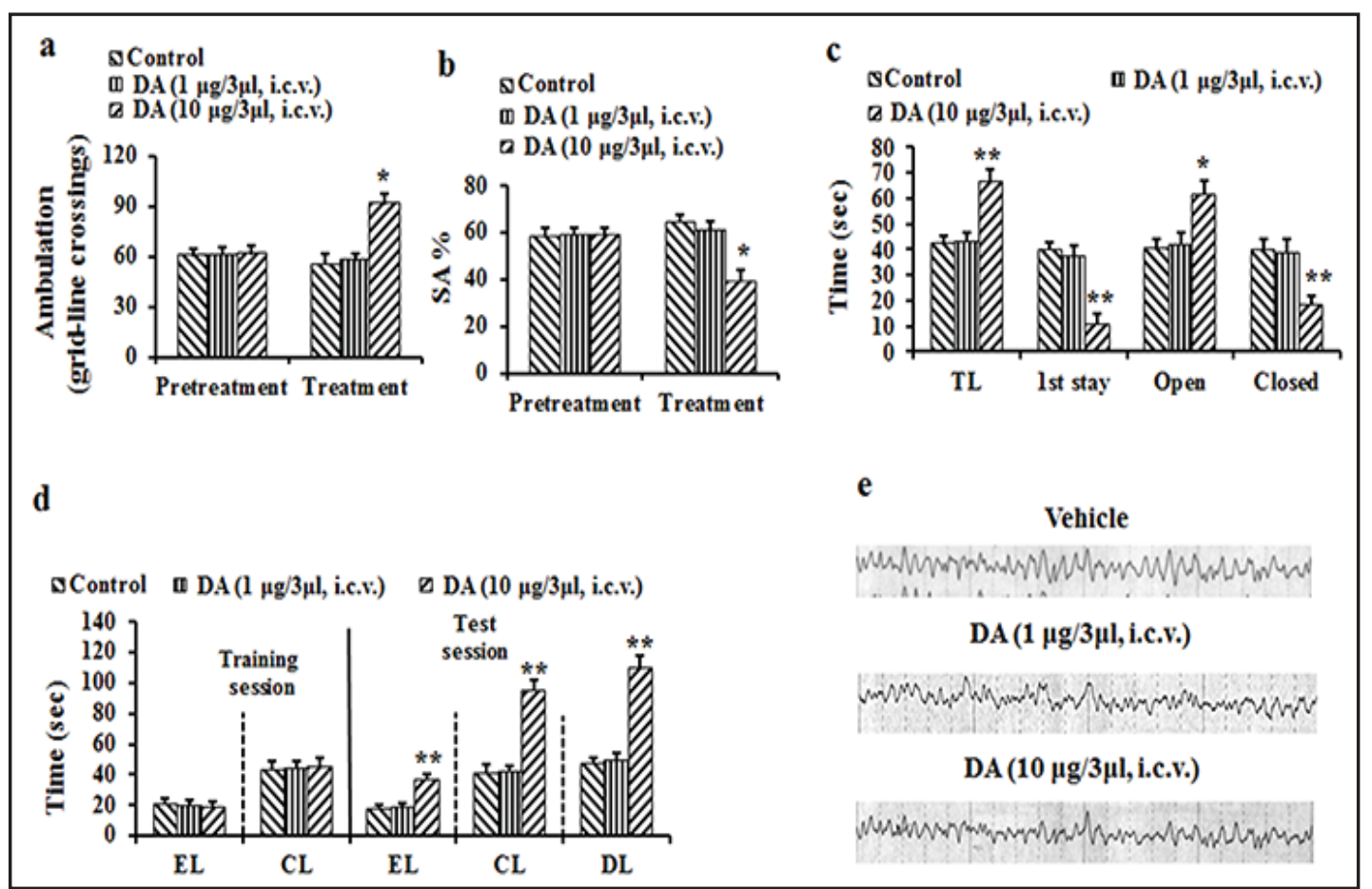

Fig. 2. The effect of intracranial elevated DA on the memory impairment. (a) Ambulation in open-field test (OF) of vehicle and DA (1 and $10 \mu \mathrm{g}$, i.c.v.) -treated rats (pretreatment, left; 8-week treatment, right). (b) Spontaneous alternation percentage (SA\%) in YM of vehicle and DA (1 and 10 $\mu$ g) -treated rats (pretreatment, left; 8-Week treatment, right). (c) Results of elevated-plus maze (EPM) (TL, transfer latency; first stay, duration of the first stay; open, time spent in the open arms; closed, time spent in the closed arms) in

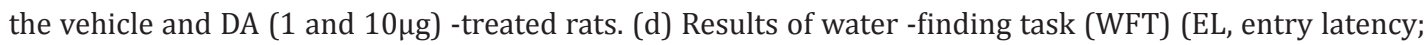
CL, contacting latency; DL, drinking latency) in the vehicle and DA (1 and $10 \mu \mathrm{g}$ ) -treated rats. (e) No Theta $(4-7 \mathrm{~Hz})$ or Delta $(<4 \mathrm{~Hz})$ bands (slow wave) were seen in EEG of DA $(10 \mu \mathrm{g})$-treated rats.

or central to central pattern (Fig. 1a and b), These observations suggested that the liver fibrosis model was successfully established.

Rats were then subjected to a series of behavioral tests: an OF test, a YM, an EPM test and a WFT. No TAA-treated rats exhibited any significant increase in voluntary activities in the OF, as compared to control groups (Fig. 1c). The SA\% in the YM for 15 TAA-treated rats out of 30 was significantly lower ( $P<0.01$ ) than that of control rats (Fig. 1d). In EPM, 18 TAAtreated rats out of 30 exhibited loss of anxiety-they stayed significantly longer in the open arms and less in the closed arms compared with controls (Fig. 1e). In WFT, TAA treatment also led to latent memory deficits: a significant delay in EL, CL and DL in 17 TAA-treated rats out of 30 was detected as compared with controls (Fig. 1f). Accordingly, there were 24 TAA-treated rats with at least one abnormal behavioral test and 6 TAA-treated rats without any abnormal behavior, suggesting 24 hepatic cirrhosis rats with MHE/HE and 6 hepatic cirrhosis rats without MHE. Of the MHE/HE rats, 18 out of 24 displayed an alpha (8-13 Hz) band in EEG tests, whereas a slow wave (Theta: 4-7 Hz or Delta $<4 \mathrm{~Hz}$ wave) was observed in 6 TAA-treated rats (Fig. 1g), suggesting there were 18 MHE rats and 6 HE rats.

We also examined the concentrations of DA in the liver, serum and cerebral cortex of MHE rats. Increased levels of DA in the liver (Fig. 1h), serum (Fig. 1i) and cerebral cortex (Fig. 1j) of MHE rats were observed, confirming the permeation of DA into the brain. These results indicated alteration of BBB permeability induced by liver cirrhosis.

DA treatment causes memory impairment

To confirm whether memory impairment in MHE rats is associated with the elevation of DA in the brain, we performed i.c.v. injection of DA (1 and $10 \mu \mathrm{g})$ into normal rats. Then 


\section{Cellular Physiology Cell Physiol Biochem 2014;34:1933-1950 \begin{tabular}{l|l} 
DOI: 10.1159/000366391 & O 2014 S. Karger AG, Basel
\end{tabular} \begin{tabular}{l|l} 
and Biochemistry Publisned onlne: November 21, 2014 & www.karger.com/cpb
\end{tabular}}

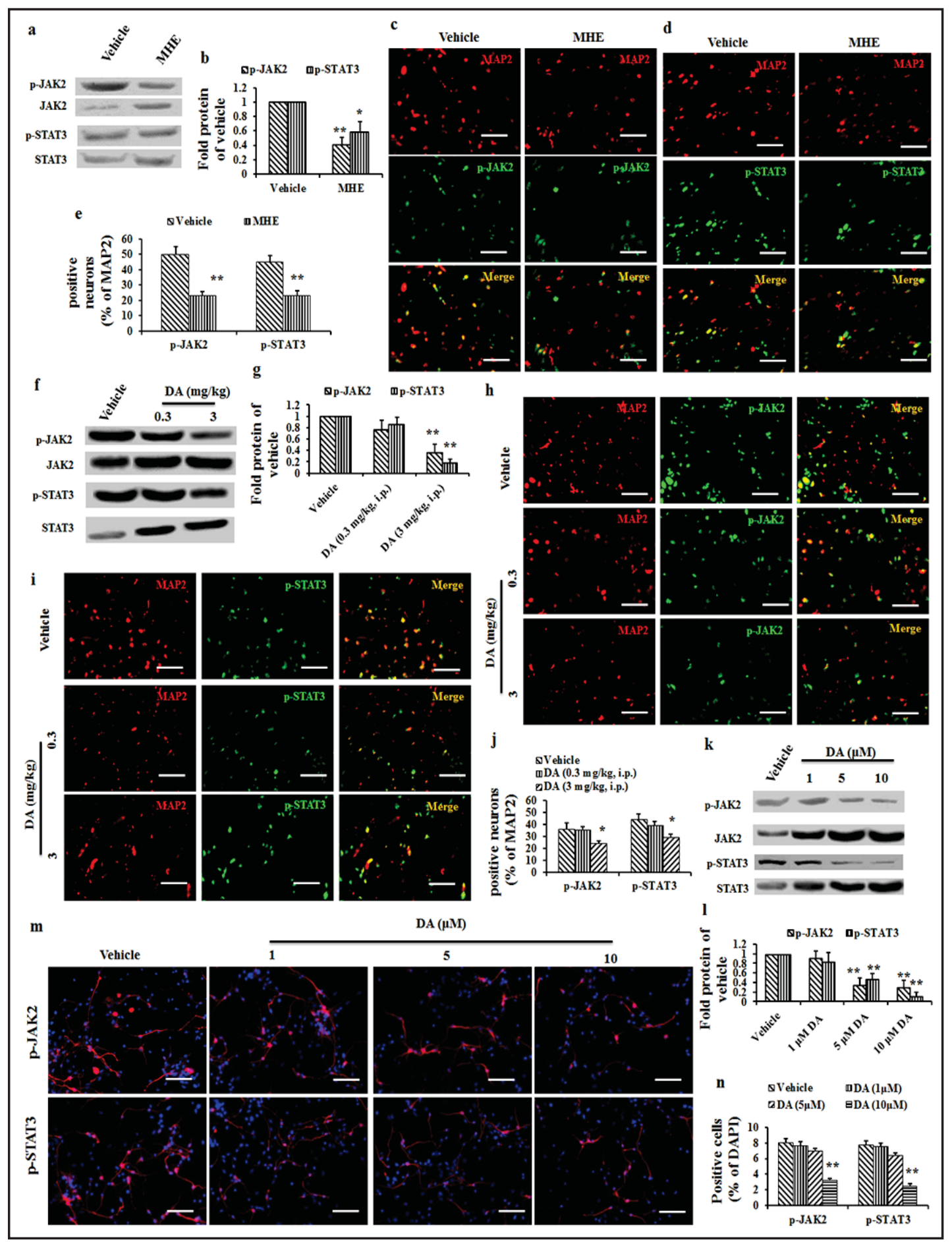

Fig. 3. The Janus kinase 2 (JAK2) /signal transducer and activator of transcription 3 (STAT3) axis was inactivated by DA in MHE models. (a) Immunoblot analysis of cerebral cortex of vehicle and MHE rats using antibodies against p-JAK2/JAK2 and p-STAT3/STAT3. (b) The change of JAK2/STAT3 phosphorylation was quantified densitometrically JAK2/STAT3 phosphorylation under the vehicle condition was set to1 and changes of JAK2/STAT3 phosphorylation are normalized to nonphosphorylated JAK2/STAT3 levels, respectively. Data are shown as mean \pm SEM. ${ }^{*} \mathrm{P}<0.05,{ }^{* *} \mathrm{P}<0.01$ vs vehicle treatment.(c, d) Colocalization of p-JAK2 (c) /p-STAT3 (d) (green) with MAP2 (a neuronal marker, red) is revealed by the overlap of signals resulting in yellow staining in the cerebral cortex regions of vehicle and MHE rats. Bar: $25 \mu \mathrm{m}$. (e) represents the ratio of the number of p-JAK2 /p-STAT3-positive cells with MAP2-positive cells in (c), (d). 


\section{Cellular Physiology and Biochemistry}

Cell Physiol Biochem 2014;34:1933-1950

\begin{tabular}{l|l}
\hline DOI: $10.1159 / 000366391$ & (C) 2014 S. Karger AG, Basel
\end{tabular}

www.karger.com/cpb

Ding et al.: Naringin Against MHE via JAK2/STAT3

Data are shown as mean \pm SEM. ${ }^{*} \mathrm{P}<0.05$, ${ }^{* *} \mathrm{P}<0.01$ vs vehicle treatment. (f) $\mathrm{p}-J A K 2 / J A K 2$ and $\mathrm{p}-\mathrm{STAT} 3 /$ STAT3 immunoreactive bands of cerebral cortex regions of vehicle and DA (1 and $10 \mu \mathrm{g})$-treated rats. (g) The change of JAK2/STAT3 phosphorylation was quantified densitometrically JAK2/STAT3 phosphorylation under the vehicle condition was set to1 and changes of JAK2/STAT3 phosphorylation are normalized to nonphosphorylated JAK2/STAT3 levels, respectively. Data are shown as mean \pm SEM. ${ }^{* *} \mathrm{P}<0.01$ vs vehicle treatment. (h, i) Double immunofluorescence (IF) staining of cerebral cortex regions of vehicle and DA (1 and $10 \mu \mathrm{g}$ ) -treated rats using antibodies against MAP2 (red) and p-JAK2 (h) /p-STAT3 (i) (green). Bar: $25 \mu$ $\mathrm{m}$. (j) represents the ratio of the number of p-JAK2/p-STAT3-positive cells with MAP2 -positive cells in (h), (i). Data are shown as mean $\pm \mathrm{SEM}$. ${ }^{*} \mathrm{P}<0.05,{ }^{* *} \mathrm{P}<0.01$ vs vehicle treatment. (k) Immunoblot (IB) analysis of primary cortical neurons (PCNs) treated with vehicle (dimethyl sulfoxide, DMSO 0.5\%), DA (1, 5 and $10 \mu \mathrm{M}$ ) using antibodies against p-JAK2/JAK2 and p-STAT3/STAT3. (l) The change of JAK2/STAT3 phosphorylation was quantified densitometrically JAK2/STAT3 phosphorylation under the vehicle condition was set to 1 and changes of JAK2/STAT3 phosphorylation are normalized to nonphosphorylated JAK2/STAT3 levels, respectively. Data are shown as mean \pm SEM. ${ }^{* *} \mathrm{P}<0.01$ vs vehicle treatment. (m) IF staining of PCNs treated with vehicle, or DA (1, 5 and $10 \mu \mathrm{M}$ ) using the anti-p-JAK2/p-STAT3 (Tyr705) antibody. Bar: $1 \mu \mathrm{m}$. (n) represents the ratio of the number of JAK2/STAT3-positive neurons with DAPI-staining neurons in (m). Data are shown as mean \pm SEM. ${ }^{*} \mathrm{P}<0.05,{ }^{* *} \mathrm{P}<0.01$ vs vehicle treatment.

rats were again subjected to behavioral tests: an OF test, a YM, an EPM test and a WFT. In the OF, increased ambulation was observed in DA (10 $\mu$ g)-treated rats (Fig. 2h). In the YM, highdoseDA (10 $\mu \mathrm{g})$-treated rats displayed a significantly different SA\% (Fig. 2i). The results of EPM showed a longer time spent in the open arms and a shorter time spent in the closed arms for DA $(10 \mu \mathrm{g})$-treated rats (Fig. 2j). In WFT, DA (10 $\mu \mathrm{g})$ treatment led to a significant delay in EL, CL and DL (Fig. 2k). An alpha (8-13 Hz) band in the EEG tests was detectable in DA-treated rats (Fig. 2l). This confirmed that elevation of DA in brain induced cognitive impairment.

\section{Cerebral DA overload causes inactivation of the JAK2/STAT3 axis}

The inactivation of the JAK2/STAT3 pathway is involved in memory impairment in AD models [4], so we examined whether memory impairment in MHE rats is associated with the inactivation of the JAK2/STAT3 pathway by $10 \mu \mathrm{g}$ DA in the brain. We first investigated whether changes in expression of JAK2/STAT3 exist in the cerebral cortexes of MHE rats using double immunofluorescence (IF) and IB. As indicated by the IB analysis shown in Fig. 3a, we confirmed reduced expression of p-JAK2/p-STAT3 in the MHE group. Similarly, MHE rats displayed a lower number of p-JAK2/p-STAT3-positive neurons than vehicle rats based on double IF staining (Fig. 3c and d).

To confirm that the inactivation of JAK2/STAT3 pathway contributes to the elevated DA in the brain, we examined the expression of p-JAK2/p-STAT3 in the cerebral cortexes of DA $(10 \mu \mathrm{g})$-treated rats using double IF and IB. Based on IB analysis, we found that the expression of p-JAK2 in DA-treated rats decreased in a dose-dependent fashion (Fig. 3f). Double IF staining of anti-p-JAK2/p-STAT3 antibody with anti-MAP2 antibody (a neuronal marker) confirmed the downregulation of p-JAK2/p-STAT3 in neurons of the cerebral cortex of DA $(10 \mu \mathrm{g})$-treated rats compared with those only exposed to vehicles (Fig. 3h and i). Thus, p-JAK2/p-STAT3 levels in the nuclei of cortical neurons were reciprocally correlated with the brain DA burden.

We further examined the effect of DA on JAK2/STAT3 phosphorylation in primary cultured neurons in vitro. Downregulation of p-STAT3 was induced only by 5 and $10 \mu \mathrm{M}$ DA treatment, but not low-dose DA $(1 \mu \mathrm{M})$ based on IB analysis (Fig. 3k) and IF staining (Fig. $3 \mathrm{~m}$ ), showing that p-JAK2/p-STAT3 was specifically induced by high concentrations of DA, which were toxic. These results implicate DA in the memory impairment of MHE by inactivation of JAK2/STAT3. 


\section{Cellular Physiology $\quad$ Cell Physiol Biochem 2014;34:1933-1950 \begin{tabular}{l|l|l}
\hline DOI: 10.1159/000366391 & (c) 2014 S. Karger AG, Basel
\end{tabular} \begin{tabular}{l|l} 
and Biochemistry Publisned onlne: November 21, 2014 & www.karger.com/cpb
\end{tabular}}

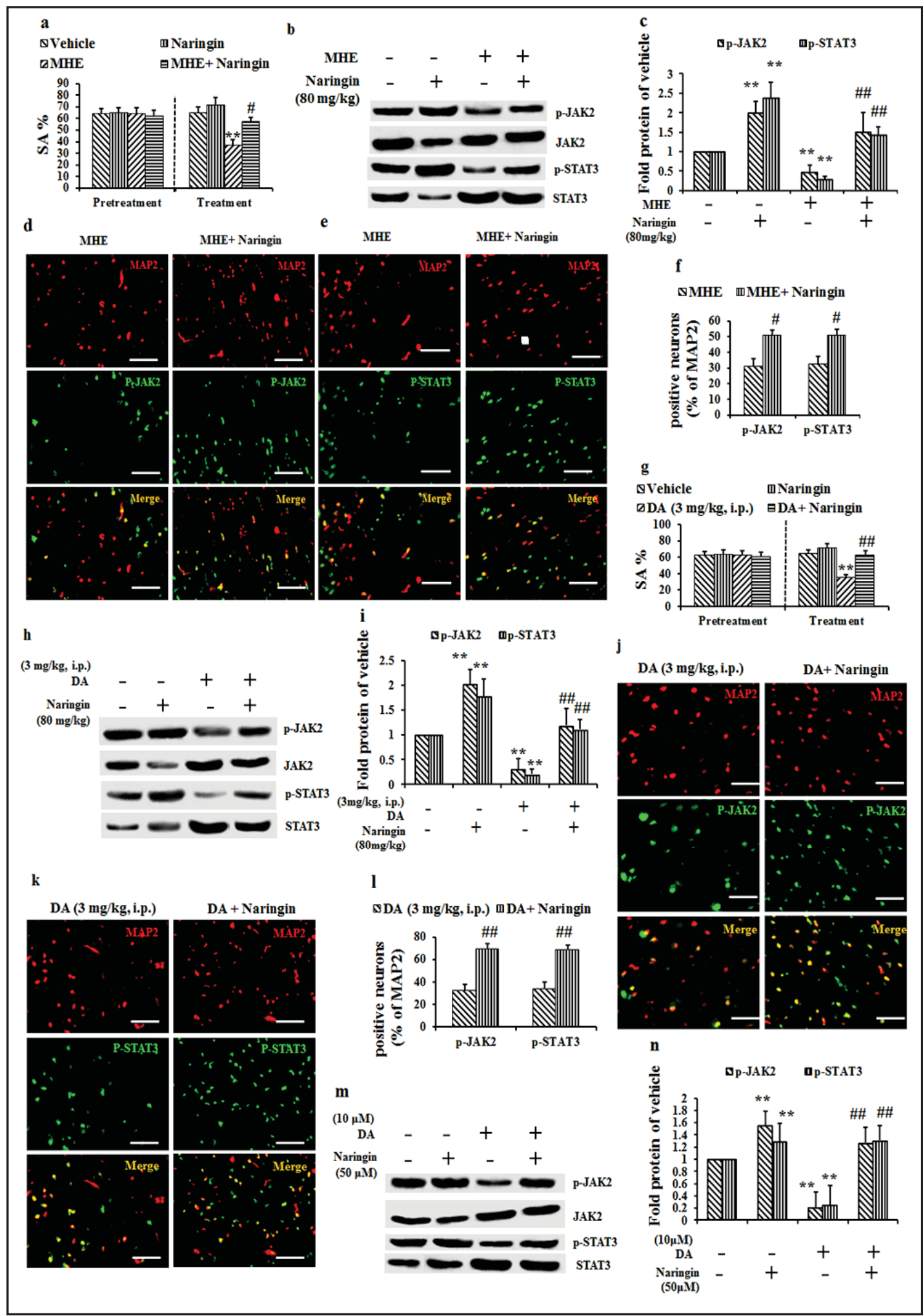

Fig. 4. Naringin improves memory impairment by activating the Janus kinase 2 (JAK2)/signal transducer and activator of transcription 3 (STAT3) axis. (a) SA\% in YM Of vehicle and MHE rats treated with or without naringin $\left(80 \mathrm{mg} / \mathrm{kg}\right.$ per injection) three times at 48 -h intervals. Data are shown as means \pm s.e.m. ${ }^{* *} \mathrm{P}$ $<0.01$ vs vehicle treatment. \# P $<0.05$ vs MHE group. (b) IB analysis of cerebral cortex of vehicle and MHE rats administered with or without naringin using antibodies against p-JAK2/JAK2 and p-STAT3/STAT3. (c) 


\section{Cellular Physiology and Biochemistry}

Cell Physiol Biochem 2014;34:1933-1950

\begin{tabular}{l|l}
\hline DOI: $10.1159 / 000366391$ & (C) 2014 S. Karger AG, Basel
\end{tabular}

www.karger.com/cpb

Ding et al.: Naringin Against MHE via JAK2/STAT3

The change of JAK2/STAT3 phosphorylation was quantified densitometrically JAK2/STAT3 phosphorylation under the vehicle condition was set to1 and changes of JAK2/STAT3 phosphorylation are normalized to nonphosphorylated JAK2/STAT3 levels, respectively. Data are shown as mean \pm SEM. ${ }^{* *} \mathrm{P}<0.01$ vs vehicle treatment; \#\# P <0.01 vs MHE group. (d, e) Colocalization of p-JAK2 (d) / p-STAT3 (e) (green) with MAP2 (a neuronal marker, red) in the cerebral cortex regions of MHE rats treated with or without naringin. Bar: $25 \mu \mathrm{m}$. (f) represents the ratio of the number of p-JAK2/p-STAT3 -positive cells with MAP2 -positive cells in (d),(e). Data are shown as mean \pm SEM. \# P $<0.05$ vs MHE group. (g) Results of Y maze (YM) of vehicle and DA $(10 \mu \mathrm{g})$-treated rats i.p. injected with or without naringin. Data are shown as mean \pm SEM. $* * \mathrm{P}<0.01 \mathrm{vs}$ vehicle treatment. \#\# P <0.01vs DA $(10 \mu \mathrm{g})$-treatment. (h) p-JAK2/JAK2 and p-STAT3/STAT3 immunoreactive bands of cerebral cortex regions of vehicle and DA $(10 \mu \mathrm{g})$-treated rats treated with or without naringin. (i) The change of JAK2/STAT3 phosphorylation was quantified densitometrically JAK2/STAT3 phosphorylation under the vehicle condition was set to1 and changes of JAK2/STAT3 phosphorylation are normalized to nonphosphorylated JAK2/STAT3 levels, respectively. Data are shown as mean \pm SEM. ${ }^{* * P}<0.01$ vs vehicle treatment; \#\# P < 0.01 vs DA $(10 \mu \mathrm{g})$-treated group. (j,k) Double IF staining of cerebral cortex regions of DA $(10 \mu \mathrm{g})$-treated rats treated with or without naringin using antibodies against MAP2 (red) and p-JAK2 (j) /p-STAT3 (k) (green). Bar: $25 \mu \mathrm{m}$. (l) represents the ratio of the number of p-JAK2/ p-STAT3-positive cells with MAP2- positive cells in (j), (k). Data are shown as mean \pm SEM. \#\# P $<0.01$ vs DA (10 $\mu g$ ) -treatment. (m) Immunoblot (IB) analysis of DA $(10 \mu \mathrm{M})$-treated PCNs with vehicle (DMSO 0.5\%) or naringin (50 $\mu \mathrm{M}$ ) treatment using antibodies against p-JAK2/JAK2 and p-STAT3/STAT3. (n) The change of JAK2/STAT3 phosphorylation was quantified densitometrically JAK2/STAT3 phosphorylation under the vehicle condition was set to1 and changes of JAK2/STAT3 phosphorylation are normalized to nonphosphorylated JAK2/ STAT3 levels, respectively. Data are shown as mean \pm SEM. ${ }^{* *} \mathrm{P}<0.01$ vs vehicle treatment; \#\# $\mathrm{P}<0.01$ vs DA $(10 \mu \mathrm{M})$-treatment.

The effect of naringin on memory impairment by activation of the JAK2/STAT3 axis

Considering that naringin improves cognitive deficits in AD [14], we treated MHE rats with naringin $(80 \mathrm{mg} / \mathrm{kg})$. Naringin induced a significant increase in $\mathrm{SA} \%$ in the $\mathrm{YM}$ compared with the MHE group (Fig. 4a). IB staining revealed that the p-JAK2/p-STAT3 levels were significantly upregulated in MHE rats treated with naringin, compared to MHE rats (Fig. 4b). In parallel, using double IF, we observed that the number of p-JAK2/p-STAT3-positive neurons was higher in MHE rats treated with naringin than in MHE rats (Fig. $4 \mathrm{~d}$ and e).

We then performed i.c.v. injection of naringin $(80 \mathrm{mg} / \mathrm{kg})$ into DA $(10 \mu \mathrm{g})$-treated rats. In the YM, naringin treatment led to memory improvement: a significant increase in SA\% in the YM was detected compared with DA-treated rats (Fig. 4g). We also confirmed that naringin significantly increased the expression of p-JAK2/p-STAT3, based on IB analysis (Fig. $4 \mathrm{~h}$ ) and double IF staining (Fig. $4 \mathrm{j}$ and $\mathrm{k}$ ), compared to DA-treated rats.

Naringin $(50 \mu \mathrm{M})$ was added to the DA $(10 \mu \mathrm{M})$-treated PCNs. The expression of p-JAK2/p-STAT3 was reversed by naringin treatment based on IB analysis (Fig. 4m). The results suggest that naringin may improve DA-induced cognitive impairment by activation of the JAK2/STAT3 axis in MHE.

Cerebral DA overload causes downregulation of cerebral cortex cholinergic neurons

Considering that A $\beta$-dependent inactivation of the JAK2/STAT3 axis causes memory loss through cholinergic dysfunction in DA models [4], we examined whether DA inactivated the JAK2/STAT3 axis by downregulating cholinergic neurons expressing an ACh producing enzyme, ChAT. We first examined the number of ChAT-positive neurons in MHE rats. A diminished number observed following AD-relevant insults such as i.c.v. injection of $A \beta$ positively correlates with spatial working memory [21]. The expression of ChAT and M1 mAChR was significantly reduced in the cerebral cortex of MHE rats compared with those treated with vehicles only based on IB analysis (Fig. 5a). Double IF staining revealed that the numbers of ChAT-positive neurons in the cerebral cortex of MHE rats was significantly fewer than those of vehicle-injected rats (Fig. 5c). We also found that the number of M1 mAChR-positive neurons in the cerebral cortex of MHE rats was significantly reduced (Fig. $5 \mathrm{~d})$. Then we found that the expression of ChAT/M1 mAChR in the cerebral cortex of MHE 


\section{Cellular Physiology $\quad$ Cell Physiol Biochem 2014;34:1933-1950 \begin{tabular}{l|l} 
DOI: 10.1159/000366391 & O 2014 S. Karger AG, Basel
\end{tabular} and Biochemistry Publisned online: November 21, 2014 www.karger.com/cpb}

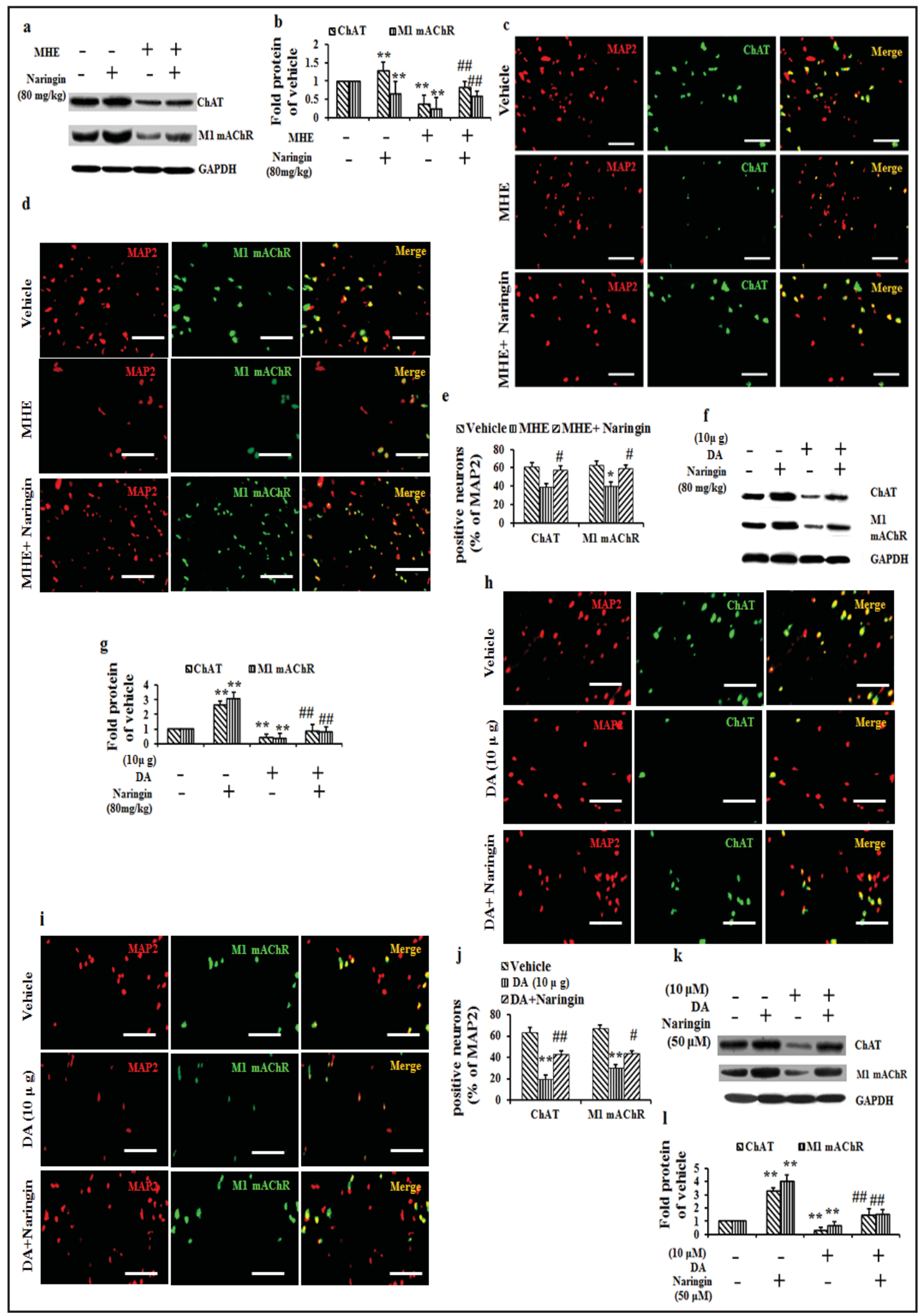

Fig. 5. DA downregulates and naringin upregulates cortical cholinergic neurons. (a) IB analysis of cerebral cortex of vehicle and MHE rats administered with or without naringin using antibodies against choline acetyltransferase (ChAT) /M1 muscarinic acetylcholine receptor (mAChR) /glyceraldehyde-3-phosphate dehydrogenase (GAPDH). (b) The change of ChAT /M1 mAChR levels was quantified densitometrically ChAT /M1 mAChR levels under the vehicle condition was set to1 and changes of ChAT /M1 mAChR levels are 


\section{Cellular Physiology and Biochemistry}

Cell Physiol Biochem 2014;34:1933-1950

\begin{tabular}{l|l}
\hline DOI: 10.1159/000366391 & (C) 2014 S. Karger AG, Basel
\end{tabular}

Publisned online: N November 21, $2014 \quad$ www.karger.com/cpb

Ding et al.: Naringin Against MHE via JAK2/STAT3

normalized to GAPDH levels. Data are shown as mean \pm SEM. ${ }^{* *} \mathrm{P}<0.01$ vs vehicle treatment; \#\# $\mathrm{P}<0.01$ vs MHE group. (c, d) Colocalization of ChAT(c) /M1 mAChR (d) (green) with MAP2 (a neuronal marker, red) in the cerebral cortex regions of MHE rats treated with or without naringin. Bar: $25 \mu \mathrm{m}$. (e) represents the ratio of the number of ChAT /M1 mAChR -positive cells with MAP2 -positive cells in (c), (d). Data are shown as mean \pm SEM. ${ }^{*} \mathrm{P}<0.05$ vs vehicle treatment; $\# \mathrm{P}<0.05$ vs MHE group. (f) ChAT/ M1 mAChR immunoreactive bands of cerebral cortex regions of vehicle and DA $(10 \mu \mathrm{g})$-treated rats treated with or without naringin. $(\mathrm{g})$ The change of ChAT /M1 mAChR levels was quantified densitometrically ChAT /M1 mAChR levels under the vehicle condition was set to1 and changes of ChAT /M1 mAChR levels are normalized to GAPDH levels. Data are shown as mean \pm SEM. ${ }^{* *} \mathrm{P}<0.01$ vs vehicle treatment; \#\# P $<0.01$ vs DA $(10 \mu \mathrm{g})$-treated group.

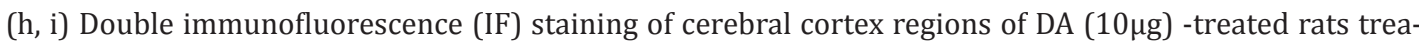
ted with or without naringin using antibodies against MAP2 (red) and ChAT (h) / M1 mAChR (i) (green). Bar: $25 \mu \mathrm{m}$. (j) represents the ratio of the number of ChAT / M1 mAChR -positive cells with MAP2-positive cells in (h), (i). Data are shown as mean \pm SEM. ${ }^{* *} \mathrm{P}<0.01$ vs vehicle treatment; \# $\mathrm{P}<0.05, \# \# \mathrm{P}<0.01$ vs DA $(10 \mu \mathrm{g})$-treatment. (k) ChAT / M1 mAChR immunoreactive bands of vehicle and DA (10 $\mu \mathrm{M})$-treated PCNs administered with or without naringin $(50 \mu \mathrm{M})$. (l) The change of ChAT /M1 mAChR levels was quantified densitometrically ChAT /M1 mAChR levels under the vehicle condition was set to1 and changes of ChAT / M1 mAChR levels are normalized to GAPDH levels. Data are shown as mean \pm SEM. ${ }^{* *} \mathrm{P}<0.01$ vs vehicle treatment; \#\# $\mathrm{P}<0.01$ vs DA $(10 \mu \mathrm{M})$-treatment.

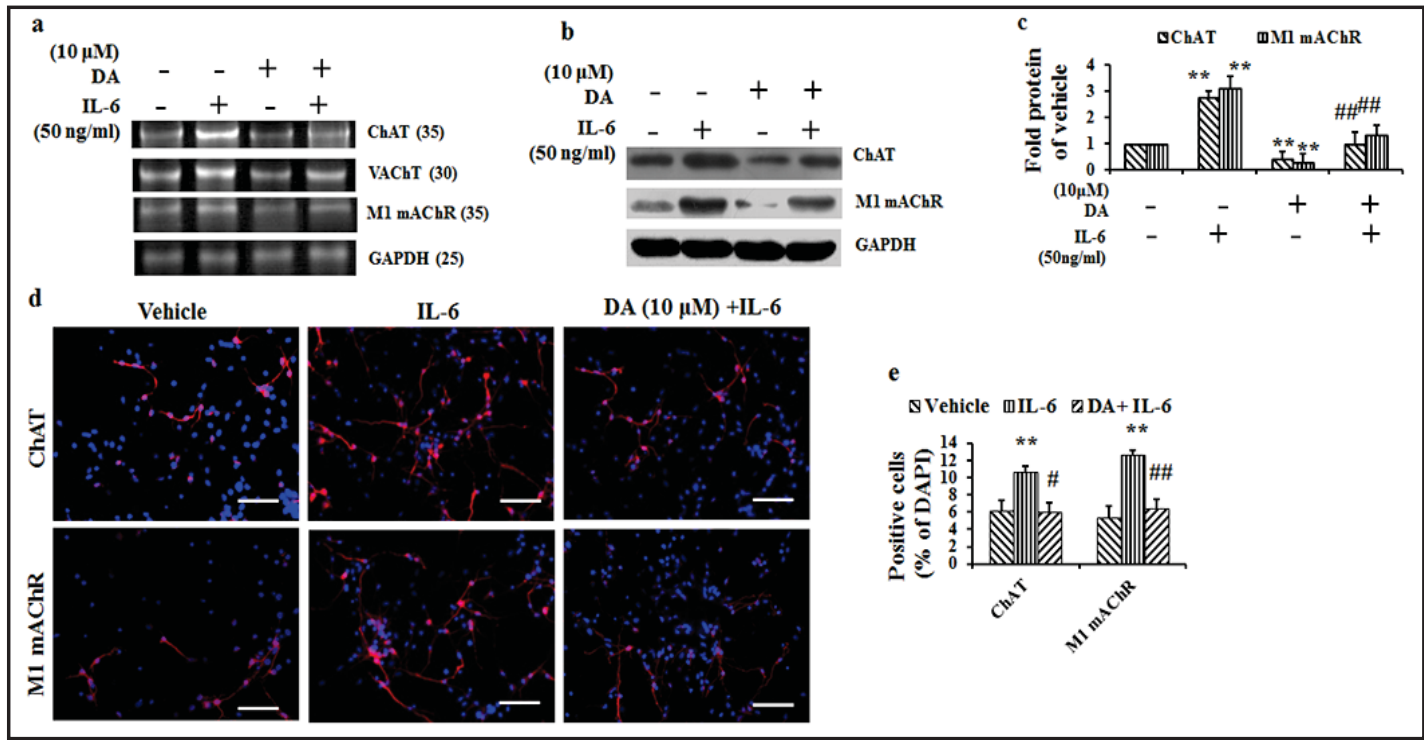

Fig. 6. DA downregulates IL-6 -mediated upregulation of cortical cholinergic neurons. (a) Semiquantitative reverse transcriptase (RT) -PCR analysis of ChAT, VAChT and M1 mAChR / GAPDH in PCNs treated with or without $10 \mu \mathrm{M}$ DA together with or without interleukin-6 (IL-6, $1 \mathrm{ng} / \mathrm{ml}$ ). Cycle numbers of PCR amplification are shown at the right sides of panels. (b) IB analysis of vehicle and DA (10 $\mu \mathrm{M})$-treated PCNs administered with or without IL-6 using antibodies against ChAT / M1 mAChR /GAPDH. (c) The change of ChAT /M1 mAChR levels was quantified densitometrically ChAT /M1 mAChR levels under the vehicle condition was set to1 and changes of ChAT /M1 mAChR levels are normalized to GAPDH levels. Data are shown as mean \pm SEM. ${ }^{* *} \mathrm{P}<0.01$ vs vehicle treatment; \#\# P $<0.01$ vs IL-6 -treatment. (d) IF staining of DA (10 $\left.\mu \mathrm{M}\right)$-treated PCNs with vehicle or interleukin-6 (IL-6, $50 \mathrm{ng} / \mathrm{ml}$ ) treatment using the ChAT / M1 mAChR antibody. Bar: $1 \mu \mathrm{m}$. (e) represents the ratio of the number of ChAT / M1 mAChR- positive neurons with DAPI -staining neurons in (d). Data are shown as mean \pm SEM. ${ }^{* *} \mathrm{P}<0.01$ vs vehicle treatment; \# $\mathrm{P}<0.05$, \#\# $\mathrm{P}<0.01$ vs IL-6-treatment.

rats, which was lower than that of normal rats, recovered to normal levels after treatment with naringin (Fig. 5a). Naringin treatment also conversely restored the number of cortical ChAT/M1 mAChRpositive neurons in MHE rats (Fig. 5c and d). IB analysis and double IF staining also revealed that ChAT and M1 mAChR levels were reduced in the cerebral cortex 


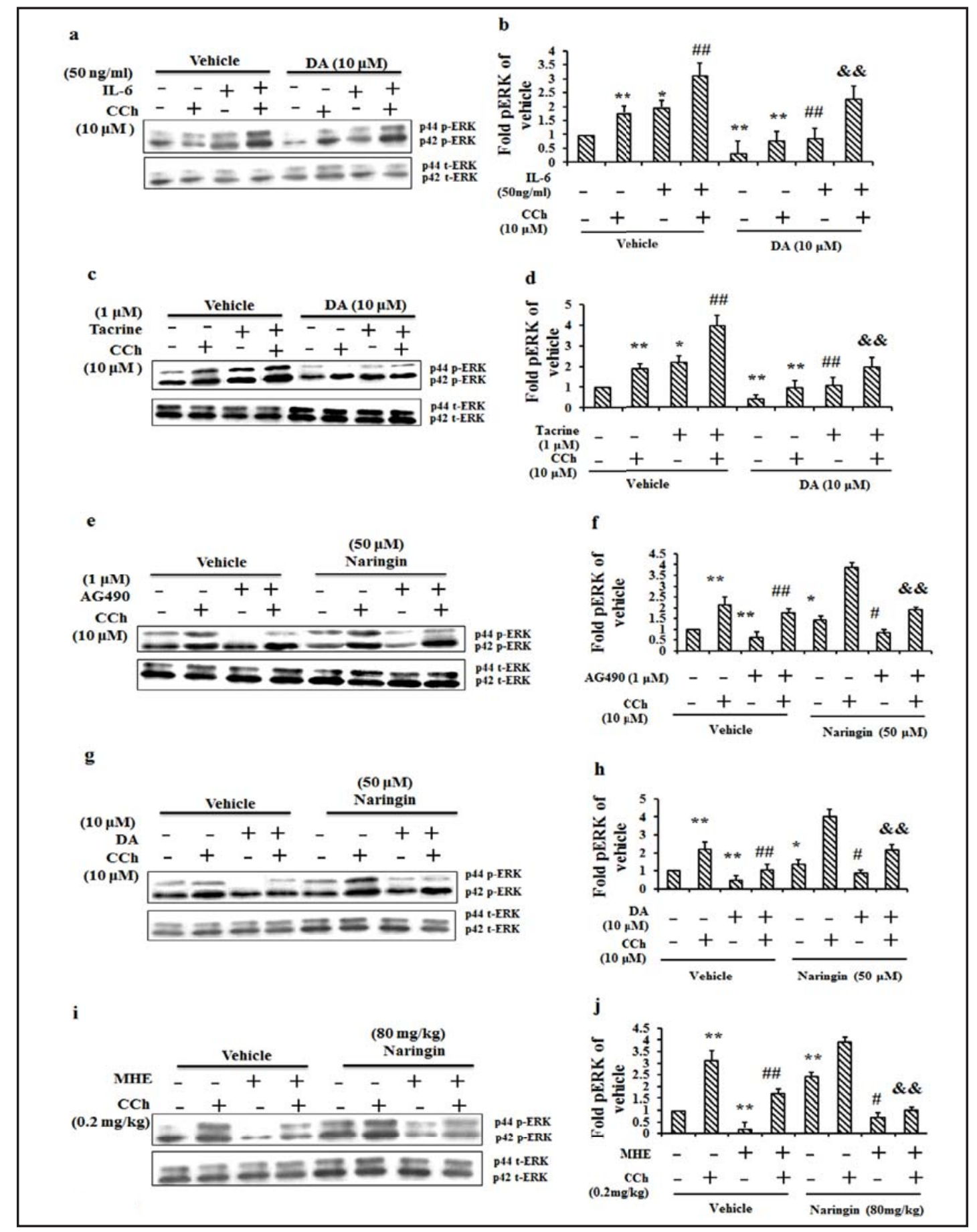

Fig. 7. DA desensitizes and naringin sensitizes the M1 Muscarinic acetylcholine receptor (M1 mAChR). (a) Effect of DMSO (0.5\%), DA $(10 \mu \mathrm{M})$ on IL-6 $(50 \mathrm{ng} / \mathrm{ml})$-mediated increase in carbachol $(\mathrm{CCh})(10 \mu \mathrm{M})$ -evoked p-ERK in PCNs by IB. (b) The change of ERK phosphorylation was quantified densitometrically ERK phosphorylation under the vehicle condition was set to1 and changes of ERK phosphorylation are normalized to nonphosphorylated ERK levels. Data are shown as mean \pm SEM. ${ }^{*} \mathrm{P}<0.05,{ }^{* *} \mathrm{P}<0.01$ vs vehicle treatment; \#\# P $<0.01$ vs IL-6 treated group; \&\& P <0.01 vs IL-6 and CCh treated group. (c) Effect of DMSO (0.5\%), DA $(10 \mu \mathrm{M})$ on tacrine (Tac, $1 \mu \mathrm{M}$ )-Mediated increase in CCh -evoked p-ERK in PCNs by IB. (d) The change of ERK phosphorylation was quantified densitometrically ERK phosphorylation under the vehicle condition was set to1 and changes of ERK phosphorylation are normalized to nonphosphorylated ERK levels. Data are shown as mean \pm SEM. ${ }^{*} \mathrm{P}<0.05,{ }^{* *} \mathrm{P}<0.01$ vs vehicle treatment; \#\# $\mathrm{P}<0.01$ vs IL-6 treated group; \&\& $\mathrm{P}$ 


\section{Cellular Physiology and Biochemistry}

Cell Physiol Biochem 2014;34:1933-1950

\begin{tabular}{l|l}
\hline DOI: $10.1159 / 000366391$ & (C) 2014 S. Karger AG, Basel
\end{tabular}

www.karger.com/cpb

Ding et al.: Naringin Against MHE via JAK2/STAT3

$<0.01$ vs IL- 6 and CCh treated group. (e) Effect of DMSO (0.5\%), naringin (50 $\mu \mathrm{M}$ ) on AG490 -Mediated decrease in carbachol (CCh) $(10 \mu \mathrm{M})$-evoked p-ERK in PCNs by IB. (f) The change of ERK phosphorylation was quantified densitometrically ERK phosphorylation under the vehicle condition was set to 1 and changes of ERK phosphorylation are normalized to nonphosphorylated ERK levels. Data are shown as mean \pm SEM. *P $<0.05$, ${ }^{* *} \mathrm{P}<0.01$ vs vehicle treatment; \# P $<0.05$, \#\# P $<0.01$ vs AG490 -treatment; \&\& P $<0.01$ vs AG490 and CCh treated group. (g) Effect of DMSO $(0.5 \%)$, naringin $(50 \mu \mathrm{M})$ on DA $(10 \mu \mathrm{M})$-mediated decrease in CCh -evoked p-ERK in PCNs by IB. (h) The change of ERK phosphorylation was quantified densitometrically ERK phosphorylation under the vehicle condition was set to1 and changes of ERK phosphorylation are normalized to nonphosphorylated ERK levels. Data are shown as mean \pm SEM. ${ }^{*} \mathrm{P}<0.05$, ${ }^{* *} \mathrm{P}<0.01$ vs vehicle treatment; \# P <0.05, \#\# P <0.01 vs AG490 -treatment; \&\& P <0.01 vs AG490 and CCh treated group. (i) Effect of naringin $(80 \mathrm{mg} / \mathrm{kg})$ on carbachol (CCh) $(0.2 \mathrm{mg} / \mathrm{kg})$-evoked extracellular signal -regulated kinase (ERK) phosphorylation in MHE rats by IB. (j) The change of ERK phosphorylation was quantified densitometrically ERK phosphorylation under the vehicle condition was set to1 and changes of ERK phosphorylation are normalized to nonphosphorylated ERK levels. Data are shown as mean \pm SEM. ${ }^{* *} \mathrm{P}<0.01$ vs vehicle treatment; \# $\mathrm{P}<0.05$, \#\# P $<0.01$ vs AG490 -treatment; \&\& $\mathrm{P}<0.01$ vs AG490 and CCh treated group.

of rats treated with DA $(10 \mu \mathrm{g})$ and that naringin treatment brought the ChAT levels back to normal levels (Fig.s 5f, $\mathrm{h}$ and i). These results suggested that cholinergic neurons are involved in DA-induced memory impairment in MHE and that the impairment of cholinergic neurons by DA was improved by naringin.

We confirmed essentially the same results in vitro in DA-treated PCNs. The ChAT and M1 mAChR levels were similarly significantly reduced in high-dose DA $(10 \mu \mathrm{M})$-treated PCNs based on IB analysis and IF staining, and naringin augmented the ChAT and M1 mAChR expression of PCNs treated with $10 \mu \mathrm{M}$ DA (Fig. 5k).

Considering that IL-6, a general STAT3 activator, upregulated ChAT mRNA expression [4], we examined the in vitro effect of DA on gene expression of ChAT by semi-quantitative RT-PCR using mRNA derived from PCNs. IL-6 upregulated vesicular acetylcholine transporter (VAChT) and ChAT as well as M1 mAChR mRNA, an effect completely inhibited by highdose DA $(10 \mu \mathrm{M})$ (Fig. 6a). Using IB to analyze the expression of ChAT/M1 mAChR proteins, we observed that IL-6-treated PCNs exhibited upregulation of ChAT/M1 mAChR, which was reversed by high-dose DA $(10 \mu \mathrm{M})$ treatment (Fig. 6b). We also found that high-dose DA reduced IL-6-mediated elevation of the number of ChAT/M1 mAChR-positive neurons in PCNs based on IF staining (Fig. 6d). This confirmed that DA inhibits JAK2/STAT3/ ChAT/M1 mAChR signaling.

\section{Desensitization of the M1 $m A C h R$ in MHE by DA}

Considering that the JAK2/STAT3 axis may regulate function of M1 mAChR in AD models [4], we examined whether DA desensitized the M1 muscarinic acetylcholine receptor by inhibiting the JAK2/STAT3 axis. As expected, p-ERK levels were substantially increased by i.p. CCh injection (Fig. 7a), and high-dose DA $(10 \mu \mathrm{M})$ decreased IL-6-mediated augmentation of CCh-induced p-ERK in PCNs (Fig. 7a). Pretreatment with tacrine, a cholinesterase inhibitor, modestly increased CCh-induced p-ERK, presumably because of the inhibition of endogenous ACh degradation, and $10 \mu \mathrm{M}$ DA suppressed tacrine-mediated augmentation of CCh-induced p-ERK in PCNs (Fig. 7c). These results suggest that M1 mAChR-mediated signals require the activation of STAT3 and M1 mAChR in inducing ERK phosphorylation.

To examine the effect of naringin on the activity of M1 mAChR, we treated CCh-injected rats with AG490 and found that CCh-induced p-ERK was inhibited by AG490 (Fig. 7e). AG490-induced suppression of CCh-evoked p-ERK in the cortical lysates was eliminated by naringin (Fig. 7e). These results suggest that naringin sensitizes M1 mAChR by activation of the JAK2/STAT3 axis. CCh-induced p-ERK in PCNs, which was inhibited by $10 \mu \mathrm{M}$ DA (Fig. 7g), recovered to normal levels after treatment with naringin. We also found that the ERK phosphorylation induced by CCh was inhibited in MHE rats, and naringin reversed the inhibition of CCh-induced p-ERK in MHE rats to close to the normal level (Fig. 7i). All the 


\section{Cellular Physiology and Biochemistry}

Cell Physiol Biochem 2014;34:1933-1950

\begin{tabular}{l|l}
\hline DOI: $10.1159 / 000366391$ & (C) 2014 S. Karger AG, Basel
\end{tabular}

www.karger.com/cpb

Ding et al.: Naringin Against MHE via JAK2/STAT3

data suggested that blocking M1 mAChR-mediated signals is involved in DA-induced memory impairment by inhibiting the JAK2/STAT3 axis in MHE.

\section{Discussion}

We here demonstrated that chronic stimulation of the cortical neurons by toxic DA significantly deteriorates the expression of the JAK2/STAT3 axis, whereas naringin inversely increased the expression of the JAK2/STAT3 axis. We also showed a critical interaction between the JAK2/STAT3 axis and the cholinergic neurotransmission system. Thus, we have provided the first evidence suggesting that the JAK2/STAT3 axis may be important in the pathogenesis of DA-related memory impairment in MHE rats.

During characterization of the pharmacological effect of naringin, we found that p-STAT3 levels in the cerebral cortex of MHE rats with memory impairment were substantially reduced, suggesting that STAT3 inactivation may be closely linked to the pathogenesis of MHE. Given that overproduction of DA is a feature for working memory in our previous study [10], and memory impairment is associated with disturbance of the JAK2/STAT3 axis in AD models [4], DA may be the major factor accelerating STAT3 inactivation during MHE.

Some studies have reported that the memory-improving effect of naringin on AD models is likely mediated either by enhancing the autophosphorylation of CaMKII, increasing the phosphorylation of the $\alpha$-amino-3-hydroxy-5-methyl-4-isoxazolepropionic receptor at a CaMKII -dependent site [14], or by directly increasing GSK-3 $\beta$ phosphorylation [25]. Additionally, our study observed that the JAK2/STAT3 axis is necessary for the pharmacological effect of naringin on MHE. Therefore, we assume that the activation of the JAK2/STAT3 axis by naringin may be stimulated by increasing phosphorylation of upstream proteins in MHE models. We also assume that STAT3-activating factors such as IL-6 may exert a pharmacological effect similar to naringin depending on activation of IL-6 receptors in MHE models.

Considering that leukemia inhibitory factor and ciliary neurotrophic factor, both of which can activate STAT3, are reported to have roles in the expression of ChAT and VAChT $[26,27]$, STAT3 activation is one of the key transcriptional factors for cholinergic neurons. We examined whether STAT3-mediated transcriptional regulation of genes related to memory was involved in memory impairment by DA. Our in vitro experiments revealed that DA suppressed IL-6-induced ChAT and VAChT expression, essential proteins for cholinergic neurons [28], in a STAT3 activity-dependent fashion. Combined with our finding that p-STAT3 activation was inhibited by toxic levels of DA, we hypothesized that a substantial portion of endogenous ChAT expression in the medial septa may be dependent on the JAK2/STAT3 axis [8].

To examine how the function of M1 mAChR is regulated by the JAK2/STAT3 axis, utilizing STAT3-activating factors such as IL-6, we found that DA desensitized M1 mAChR to CCh stimulation by inhibiting activation of STAT3; utilizing tacrine, a cholinesterase inhibitor, we found that sensitization of the M1 mAChR was attributable to ACh, the ligand of the M1 mAChR. During characterization of the naringin-mediated memory-improving effect, we found that naringin sensitized M1 mAChR to CCh stimulation by activating the JAK2/STAT3 axis in MHE models.

Numerous inconsistent studies described specific effects of DA manipulations on learning. Some studies showed that learning and retention of memory, required for optimal response choice, are significantly reliant on dopamine in Alzheimer's Disease [29, 30]. However, some studies found that dopamine impairs or have no effect on, stimulus-response learning and working memory in Parkinsonism or MHE [31-33], similarly in our present study we displayed that overproduction of DA is a feature for memory impairment in MHE. Brodskii VY et al reported that dopamine disorganizes the rhythm of protein synthesis in hepatocytes in vitro and in vivo [34,35], indicating the relationship of elevation of DA with liver cirrhosis on the other side. 


\section{Cellular Physiology and Biochemistry}

Cell Physiol Biochem 2014;34:1933-1950

\begin{tabular}{l|l}
\hline DOI: $10.1159 / 000366391$ & (C) 2014 S. Karger AG, Basel
\end{tabular}

www.karger.com/cpb

Ding et al:: Naringin Against MHE via JAK2/STAT3

Liver-brain signaling mechanisms in liver failure include altered permeability of the BBB [36]. The development of acute liver failure occurs together with BBB breakdown [37]. A number of substances such as ammonia, serotonin, bradykinin, adenosine, purine nucleotides, interleukins, free radicals, nitric oxide, and steroids may influence the brain endothelium function and tightness of the BBB [38]. Inflammation-related BBB permeability changes in acute liver failure [39]. Hepatitis $\mathrm{C}$ virus (HCV)-related neurocognitive dysfunction has been believed to be a consequence of cirrhosis-associated hepatic encephalopathy. Recently, HCV sequences have been detected in cerebrospinal fluid and brain tissue in chronically infected individuals, suggesting that $\mathrm{HCV}$ might cross the BBB and could affect cognitive functions [40]. [36] herefore, BBB disturbances are considered to be involved in the development of liver cirrhosis. The mechanism behind impaired permeability of the BBB appears to be important for the passage of DA into the brain in the development of MHE.

We previously found that COMT inhibitor, a protein involved in accumulation of DA, is up-regulated in cirrhotic liver in MHE by two-dimensional gel electrophoresis/mass spectrometry. COMT inhibitor is a protein involved in accumulation of DA. We then detected that the increased levels of DA in cirrhotic liver [10]. Brodskii et al. reported that DA disorganizes the rhythm of protein synthesis in hepatocytes in vitro and in vivo, indicating a relationship of elevation of DA with liver cirrhosis on the other side [34, 35]. Chronic HE patients exhibit abnormalities in the dopaminergic systems, including a decreased density of pallidal DA D2 receptors [41] and an increased brain content of DA metabolites [42]. An increased catabolism of DA caused alteration of DA reuptake in HE [43]. However, a possibly increased turnover of DA was found in the brain during HE [44], and the thioacetamide model of HE impairs two glutamate-dependent aspects of DA function in the striatum: the $\mathrm{N}$-methyl-D-aspartic acid (NMDA) -dependent DA release in vitro [45] and the accumulation of DA metabolites in vivo [46]. Altered content of DA is involved in pathogenesis of HE, tempting speculation that the elevated DA of cirrhotic livers, leading to increased DA in the brain, might induce the memory impairment of MHE.

\section{Conclusion}

We propose a hypothesis accounting for memory dysfunction in MHE: DA from cirrhotic liver was elevated in the bains of MHE models, and DA-dependent inactivation of the JAK2/ STAT3 signaling axis and downregulation of downstream M1 mAChR causes memory impairment related to MHE. Our findings provide not only a novel pathological hallmark in MHE but also a novel target in MHE therapy. Notably, the functional deterioration in the JAK2/STAT3 axis was reversed, concomitantly with memory improvement, by naringinmediated direct activation of the JAK2/STAT3 axis. The receptors involved in DA-induced memory impairment will be further investigated.

\section{Acknowledgements}

This study was funded by the Natural Science Foundation of China (81300308, 81171088, 81371396).

\section{References}

1 Aaronson DS, Horvath CM: A road map for those who don't know JAK-STAT. Science 2002;296:1653-1655.

2 Levy DE, Darnell JE Jr: Stats: transcriptional control and biological impact. Nat Rev Mol Cell Biol

2002;3:651-662.

-3 Li WX: Canonical and non-canonical JAK-STAT signaling. Trends Cell Biol 2008;18:545-551. 


\section{Cellular Physiology and Biochemistry}

Cell Physiol Biochem 2014;34:1933-1950

\begin{tabular}{l|l}
\hline DOI: 10.1159/000366391 & (C) 2014 S. Karger AG, Basel
\end{tabular}

Ding et al.: Naringin Against MHE via JAK2/STAT3

4 Chiba T, Yamada M, Sasabe J, Terashita K, Shimoda M, Matsuoka M, Aiso S: Amyloid-beta causes memory impairment by disturbing the JAK2/STAT3 axis in hippocampal neurons. Mol Psychiatry 2009;14:206-222.

-5 Chiba T, Yamada M, Aiso S: Targeting the JAK2/STAT3 axis in Alzheimer's disease. Expert Opin Ther Targets 2009;13:1155-1167.

6 Park SJ, Shin EJ, Min SS, An J, Li Z, Hee Chung Y, Hoon Jeong J, Bach JH, Nah SY, Kim WK, Jang CG, Kim YS, Nabeshima YI, Nabeshima T, Kim HC: Inactivation of JAK2/STAT3 Signaling Axis and Downregulation of M1 mAChR Cause Cognitive Impairment in klotho Mutant Mice, a Genetic Model of Aging. Neuropsychopharmacol 2013;38:1426-1437.

7 Anagnostaras SG, Murphy GG, Hamilton SE, Mitchell SL, Rahnama NP, Nathanson NM, Silva AJ: Selective cognitive dysfunction in acetylcholine M1 muscarinic receptor mutant mice. Nat Neurosci 2003;6:51-58.

-8 Caccamo A, Oddo S, Billings LM, Green KN, Martinez-Coria H, Fisher A, LaFerla FM: M1 receptors play a central role in modulating AD-like pathology in transgenic mice. Neuron 2006;49:671-682.

-9 Tan HH, Lee GH, Thia KT, Ng HS, Chow WC, Lui HF: Minimal hepatic encephalopathy runs a fluctuating course: results from a three-year prospective cohort follow-up study. Singap Med J 2009;50:255-260.

10 Ding S, Liu L, Jing H, Xie J, Wang X, Mao J, Zhang X, Chen B, Zhuge QC: Dopamine from cirrhotic liver contributes to the impaired learning and memory ability of hippocampus in minimal hepatic encephalopathy. Hepa Int 2013;7:923-936. Doi 10.1007/s12072-013-9431-6.

-11 Schroeter H, Boyd C, Spencer JP, Williams RJ, Cadenas E, Rice-Evans C: MAPK signaling in neurodegeneration: influences of flavonoids and of nitric oxide. Neurobiol Aging 2002;23:861-880.

12 Golechha M, Chaudhry U, Bhatia J, Saluja D, Arya DS: Naringin protects against kainic acid-induced status epilepticus in rats: evidence for an antioxidant, anti-inflammatory and neuroprotective intervention. Biol Pharm Bull 2011;34:360-365.

13 Kumar P, Kumar A: Protective effect of hesperidin and naringin against 3-nitropropionic acid induced Huntington's like symptoms in rats: possible role of nitric oxide. Behav Brain Res 2010;206:38-46.

14 Wang DM, Yang YJ, Zhang L, Zhang X, Guan FF, Zhang LF: Naringin Enhances CaMKII Activity and Improves Long-Term Memory in a Mouse Model of Alzheimer's Disease. Int J Mol Sci 2013;14:5576-5586.

15 Kumar A, Dogra S, Prakash A: Protective effect of naringin, a citrus flavonoid, against colchicine-induced cognitive dysfunction and oxidative damage in rats. J Med Food 2010;13:976-984.

16 Kumar A, Prakash A, Dogra S: Naringin alleviates cognitive impairment, mitochondrial dysfunction and oxidative stress induced by D-galactose in mice. Food Chem Toxicol 2010;48:626-632.

-17 Prakash A, Shur B, Kumar A: Naringin protects memory impairment and mitochondrial oxidative damage against aluminium-induced neurotoxicity in rats. Int J Neurosci 2013;123:636-645.

18 Maratha SR, Mahadevan N: Memory enhancing activity of naringin in unstressed and stressed mice: possible cholinergic and nitriergic modulation. Neurochem Res 2012;37:2206-2212.

19 Jia L, Zhang MH: Comparison of probiotics and lactulose in the treatment of minimal hepatic encephalopathy in rats. World J Gastroentero 2005;11:908-911.

-20 Kawasumi M, Chiba T, Yamada M, Miyamae-Kaneko M, Matsuoka M, Nakahara J, Tomita T, Iwatsubo T, Kato S, Aiso S, Nishimoto I, Kouyama K: Targeted introduction of V642I mutation in amyloid precursor protein gene causes functional abnormality resembling early stage of Alzheimer's disease in aged mice. Eur J Neurosci 2004;19:2826-2838.

-21 Yamada M, Chiba T, Sasabe J, Nawa M, Tajima H, Niikura T, Terashita K, Aiso S, Kita Y, Matsuoka M, Nishimoto I: Implanted cannula-mediated repetitive administration of Abeta25-35 into the mouse cerebral ventricle effectively impairs spatial working memory. Behav Brain Res 2005;164:139-146.

-22 Itoh J, Nabeshima T, Kameyama T: Utility of an elevated plus-maze for the evaluation of memory in mice: effects of nootropics, scopolamine and electroconvulsive shock. Psychopharmacology1990;101:27-33.

23 Mamiya T, Noda Y, Nishi M, Takeshima H, Nabeshima T: Enhancement of spatial attention in nociceptin/ orphanin FQ receptor-knockout mice. Brain Res 1998;783:236-240.

-24 Marini AM, Paul SM: N-methyl-D-aspartate receptor-mediated neuroprotection in cerebellar granule cells requires new RNA and protein synthesis. Proc Natl Acad Sci USA 1992;89:6555-6559.

25 Wang D, Gao K, Li X, Shen X, Zhang X, Ma C, Qin C, Zhang L: Long-term naringin consumption reverses a glucose uptake defect and improves cognitive deficits in a mouse model of Alzheimer's disease. Pharmacol Biochem Behav 2012;102:13-20. 


\section{Cellular Physiology and Biochemistry}

Cell Physiol Biochem 2014;34:1933-1950

\begin{tabular}{l|l}
\hline DOI: $10.1159 / 000366391$ & (C) 2014 S. Karger AG, Basel
\end{tabular}

Published onlıne: November 21, $2014 \quad$ www.karger.com/cpb

Ding et al.: Naringin Against MHE via JAK2/STAT3

-26 Berse B, Blusztajn JK: Coordinated up-regulation of choline acetyltransferase and vesicular acetylcholine transporter gene expression by the retinoic acid receptor alpha, cAMP, and leukemia inhibitory factor/ ciliary neurotrophic factor signaling pathways in a murine septal cell line. J Biol Chem 1995;270:2210122104.

27 Cheema SS, Arumugam D, Murray SS, Bartlett PF: Leukemia inhibitory factor maintains choline acetyltransferase expression in vivo. Neuroreport 1998;9:363-366.

-28 Bartus RT, Dean RL, 3rd., Beer B, Lippa AS: The cholinergic hypothesis of geriatric memory dysfunction. Science 1982;217:408-414.

-29 Coulthard EJ, Bogacz R, Javed S, Mooney LK, Murphy G, Keeley S, Whone AL: Distinct roles of dopamine and subthalamic nucleus in learning and probabilistic decision making. Brain 2012;135:3721-3734.

- 30 Shiner T, Seymour B, Wunderlich K, Hill C, Bhatia KP, Dayan P, Dolan RJ: Dopamine and performance in a reinforcement learning task: evidence from Parkinson's disease. Brain 2012;135:1871-1883.

- 31 Kobza S, Ferrea S, Schnitzler A, Pollok B, Sudmeyer M, Bellebaum C: Dissociation between active and observational learning from positive and negative feedback in Parkinsonism. Plos One 2012;7:e50250.

32 Moustafa AA, Herzallah MM, Gluck MA: Dissociating the cognitive effects of levodopa versus dopamine agonists in a neurocomputational model of learning in Parkinson's disease. Neurodegener Dis 2013;11:102-111.

33 Ding SD, Liu LP, Jing HJ, Xie JY, Wang XB, Mao JP, Chen BC, Zhuge QC: Dopamine from cirrhotic liver contributes to the impaired learning and memory ability of hippocampus in minimal hepatic encephalopathy. Hepa Inter 2013;7:923-936.

34 Brodskii VY, Dubovaya TK, Zvezdina ND, Konchenko DS, Mal'chenko LA: Dopamine disorganizes the rhythm of protein synthesis disrupting self-organization of hepatocytes in vitro. B Exp Biol Med+2013;156:38-40.

35 Brodskii VY, Mal'chenko LA, Dubovaya TK, Konchenko DS, Zvezdina ND: Administration of Dopamine to Rats Disorganizes the Rhythm of Protein Synthesis in Hepatocytes. B Exp Biol Med+ 2014;157:220-223.

-36 Butterworth RF: The liver-brain axis in liver failure: neuroinflammation and encephalopathy. Nat Rev Gastro Hepat 2013;10:522-528.

-37 Martins YC, Daniel-Ribeiro CT: A new hypothesis on the manifestation of cerebral malaria: the secret is in the liver. Med Hypotheses 2013;81:777-783.

38 Skowronska M, Albrecht J: Alterations of blood brain barrier function in hyperammonemia: an overview. Neurotox Res 2012;21:236-244.

-39 Chastre A, Belanger M, Nguyen BN, Butterworth RF: Lipopolysaccharide precipitates hepatic encephalopathy and increases blood-brain barrier permeability in mice with acute liver failure. Liver Int DOI:10.1111/liv.12252.

40 Abdel Rahman TT, Abou Hashem RM, Abdel Guaad MA, Mortagy AK: Executive functions in chronic hepatitis C virus-infected elderly patients. Geriatr Gerontol Int DOI:10.1111/ggi.12187.

-41 Mousseau DD, Perney P, Layrargues GP, Butterworth RF: Selective loss of pallidal dopamine D2 receptor density in hepatic encephalopathy. Neurosci Lett 1993;162:192-196.

42 Bergeron M, Reader TA, Layrargues GP, Butterworth RF: Monoamines and metabolites in autopsied brain tissue from cirrhotic patients with hepatic encephalopathy. Neurochem Res 1989;14:853-859.

43 Weissenborn K, Berding G, Kostler H: Altered striatal dopamine D2 receptor density and dopamine transport in a patient with hepatic encephalopathy. Metabolic Brain Dis 2000;15:173-178.

44 Knell AJ, Davidson AR, Williams R, Kantamaneni BD, Curzon G: Dopamine and serotonin metabolism in hepatic encephalopathy. Brit Med J (BMJ) 1974;1:549-551.

45 Borkowska HD, Oja SS, Oja OS, Saransaari P, Hilgier W, Albrecht J: N-methyl-D-aspartate-evoked changes in the striatal extracellular levels of dopamine and its metabolites in vivo in rats with acute hepatic encephalopathy. Neurosci Lett 1999;268:151-154.

-46 Borkowska HD, Oja SS, Saransaari P, Albrecht J: Release of [3H]dopamine from striatal and cerebral cortical slices from rats with thioacetamide-induced hepatic encephalopathy: different responses to stimulation by potassium ions and agonists of ionotropic glutamate receptors. Neurochem Res 1997;22:101-106. 